\title{
How To Create Interest In Technical Presentations
}

\author{
Paul J. Antaki \\ Antaki \& Associates, Inc.
}

\section{Importance of Creating Interest}

Technical presentations play an important role in our careers as engineers and scientists, and in educating students for these careers. For example, delivering successful conference presentations gains recognition for our work. Further, "selling" the work to managers or customers often involves its presentation. Here, I summarize an approach to help motivate an audience to attend, then listen to, a presentation.

Developing this motivation is a key ingredient for a successful presentation, since the audience is likely to be less interested in its topic than the speaker. From a speaker's perspective, for instance, his or her presentation is the most important one at a conference. To the audience, however, it's just one of many. Also, audiences usually expect presentations to be boring descriptions of technical facts understood only by the "experts."

In the next several sections I show how to motivate audiences encountered in three common scenarios: (i) project review given "in house" at a company, (ii) project report delivered to a customer, (iii) conference paper. First, I discuss these scenarios using a case study. Then, I provide other examples including one for a student presentation.

\section{a. Role of case study}

\section{Overall Approach For Creating Interest}

Case studies help teach application of theory in engineering and science by examining real-life problems and their solutions. I use case studies for teaching technical presentation skills.

In the study used here, the ABC Corporation (a fictitious company) designs and manufactures copper cable for electric utilities. Unfortunately, a new type of cable has an excessive thickness of rubber insulation. As a result, the heat generated in the copper from the flow of electric current causes melting of the copper and failure of the cable. This failure leaves thousands of utility customers without power for several days. The power loss is a catastrophe for the utility, since its purpose is to provide uninterrupted power. In turn, it's a catastrophe for the ABC Corporation.

After the failure, the $\mathrm{ABC}$ Corporation requests proposals from several engineering firms. The request calls for investigating the failure and recommending an insulation thickness that permits sufficient heat loss from the copper to prevent melting, while satisfying the thickness criterion for electrical insulation. 
The firm that wins the contract analyzes the failure and develops a unique design that satisfies the thermal and electrical criteria. In addition, this design can be applied to other cables manufactured by the $\mathrm{ABC}$ Corporation, opening the door to future business for this engineering firm.

In three separate presentations, the firm's project leader (the "speaker") delivers the final report of the work to audiences in the scenarios listed previously. The speaker's overall analysis for motivating each audience to attend the presentation, then listen to it, is described next.

\section{b. Speaker's analysis}

The key features of the analysis are judgments made by the speaker based on information available about the audience expected for each presentation. Thus, the speaker's first task is to identify the "target audience." The target here is very common: People with a general background in science and engineering who are not experts in the work being presented. The target can also contain "decision makers" or experts, as shown shortly.

Second, the speaker assumes the perspective of the target audience and asks:

$\checkmark$ Why should I attend this presentation?

$\checkmark$ Why should I listen to the speaker, once in attendance?

This deliberate shift of perspective from speaker to audience is critical because the audience, not the speaker, decides whether a presentation is successful. In fact, a common cause of unsuccessful presentations is the failure to make this shift.

The answers to these two questions are the "title" and "focal point, " respectively, of each presentation. Here's the key point: taken together, the title and focal point motivate the audience by creating an overall theme that is interesting to the audience. Without this interest, for example, an audience can quickly become impatient during a presentation and say: "Your work has no importance, so it's not worth listening to. "More specifically:

Title: The title generates sufficient interest to motivate the audience to attend the presentation. At first glance, the title may seem trivial, but it's often the only information available to prospective members of the audience for deciding whether to attend. For instance, conference participants scan long lists of paper titles, while the staffs at companies glance at bulletin boards announcing project reviews.

Focal Point: The focal point is the reason an audience listens to a presentation after it begins. Ideally, it "focuses" attention on the issue of greatest importance to the audience. Typically, this issue is the key benefit or result arising from the work - from the audience's perspective. For example, the technical objective of "deriving the heat loss equation" may be the speaker's primary interest, while the business objective of "avoiding the cost of cable replacements" may be of greatest importance to the audience.

\section{a. In-house project review}

\section{Three Scenarios}

This presentation can help the speaker advance in the firm by showing ability to solve technical problems the customer considers important, while generating the in-house visibility and new business required for promotion to a high level. Thus, the speaker wants to assemble a large target audience that includes the "decision makers" (partners, executives, etc.) on promotions. Hence, the speaker first selects 
a title wing the overall importance of the work, then a focal point geared toward the decision makers.

Title: Preventing the Catastrophic Melting of Copper Cable. This title emphasizes the importance of the work by including the word "catastrophic." (Of course, this claim of importance must be supported in the presentation.) In contrast, a title implying less importance is: Preventing the Melting of Copper Cable.

Focal Point: Unique Approach Will Generate New Business. This focal point highlights the issue of greatest importance to-the decision makers: additional business will arise from this clever technical work (rather than just a one-time contract). The corresponding narration by the speaker could be: "During this presentation, I'll show how our unique technical approach can lead to additional business from this customer."

In summary, Figures 1 and 2 show the first two slides of the presentation. They state the presentation is important enough to attend (title), then listen to (focal point).

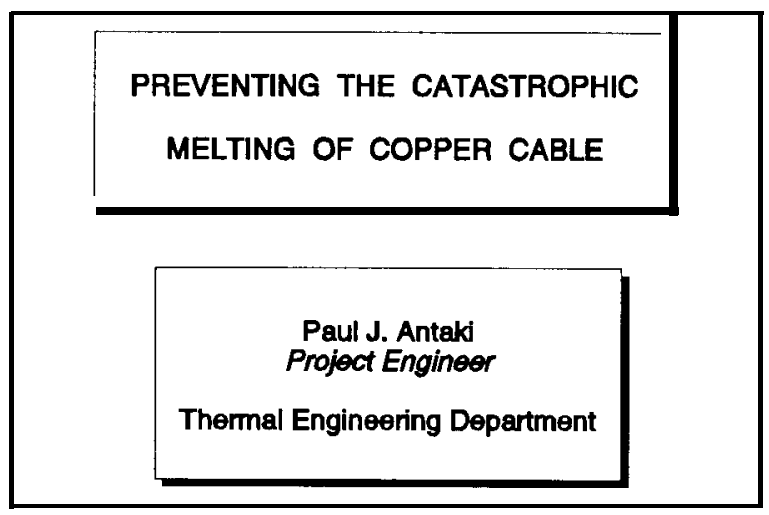

Fig. 1. Title slide for "in house" presentation



Fig. 2. Focal Point slide for "in house" presentation

\section{b. Report to customer}

Here, the speaker wants to satisfy the ABC Corporation that the work has been performed properly. The decision makers in this target audience are the contract monitors evaluating whether the work actually solves the melting problem.

Title: How To Prevent Melting of Copper Cable. This title includes the words "how to" to explicitly state the work prevents future catastrophes. However, "catastrophe" is excluded to tactfully avoid reminding the customer of the embarrassing failure. In comparison, the title: An Investigation of Copper Cable Melting, is less explicit, since it doesn't state the problem is solved - only investigated.

Focal Point: Easy, Low Cost Method To Prevent Melting. This focal point immediately states the solution is practical (and the project money is well-spent). Without this statement, the audience could become restless, then stop the speaker during the presentation to demand: "Get to the bottom line: Is it practical or not?"

\section{c. Conference paper}

In this scenario, the speaker can enhance his or her professional reputation by emphasizing the unique technical aspect of the work, instead of the business issues. This target audience includes experts in the speaker's technical specialty. 
Title: A New Method To Prevent Cable Melting. This title claims the work advances the "state of the art" of this specialty, rather than just reproducing an existing analysis. This claim would be of interest to experts and non-experts, since both could benefit by learning the new method. Alternatively, the title: An analysis of Cable Melting, would generate less interest by not taking advantage of the unique technical aspect of the work.

Focal Point: Unique Heat Transfer Analysis To Prevent Cable Melting. This focal point reminds the audience the presentation provides a new analysis tool. Thus, listening to the presentation is worthwhile. Further, the phrase "Heat Transfer Analysis" would be of specific interest to the "analysis experts" in the audience.

\section{a. Title or focal point?}

\section{More About Focal Points}

It's sometimes possible for a title and focal point to be interchanged or consolidated. For instance, both emphasize "unique" (new) in the conference paper just described. However, having separate statements for each is often a good practice. For instance, when a session chair at a conference introduces a speaker and presentation, the audience may not hear the presentation's title, since it's still "settling down. "Thus, the focal point gives the speaker a second opportunity to claim the presentation is not just a statement of routine technical facts.

\section{b. Examples of focal points}

In general, an effective focal point depends on the specific audience and its decision makers, as well as the theme the speaker wants to set for a presentation. For example, the focal point can state consequences:

- Positive consequences of taking the action proposed by the speaker: Saving or making money, beating the competition to market, etc.

- Negative consequences of not taking the proposed action: Equipment failure, loss of market share, etc.

Or, the focal point can state a key question the audience wants answered by the end of the presentation. One example is: Can We Survive The Cut-Backs In Defense Spending? In this "question and answer" approach, the question ideally motivates the audience to listen long enough to hear the answer and supporting information.

Also, students can incorporate focal points into their academic presentations. For example, suppose a group of laboratory students presents the results of an experiment that all groups will eventually perform. If the other groups have not yet performed it, a possible focal point is: Three Ways To Save Time During The Experiment. The corresponding narration could be: "During this presentation, we'll show three ways you can save time when performing the experiment."

\section{c. Caution: Does the focal point make sense?}

A pitfall in using a focal point is selecting one that doesn't make sense to the audience, thus potentially confusing it. I recently avoided this pitfall when delivering a presentation at a heat transfer conference. The subject of my presentation was a niche topic in heat transfer termed "non-Fourier heat conduction." That is, conduction not described by the classical model of Fourier's Law. This law states: Heat flux is directly proportional to the temperature gradient. 
I did not assume the audience would be familiar with this niche topic, despite the "heat transfer" nature of the conference (my assumption turned out to be correct). Thus, I avoided focal points such as: First Review Of Analytical Solutions For Non-Fourier Conduction. (Alternatively, if the audience were familiar with this topic, then "First" could generate significant interest.)

Instead, I judged the audience would be familiar with only classical Fourier conduction, because it's taught in every undergraduate heat transfer course. Hence, I relied on this familiarity to select a meaningful focal point. Figure 3 shows the focal point, using the question and answer approach.

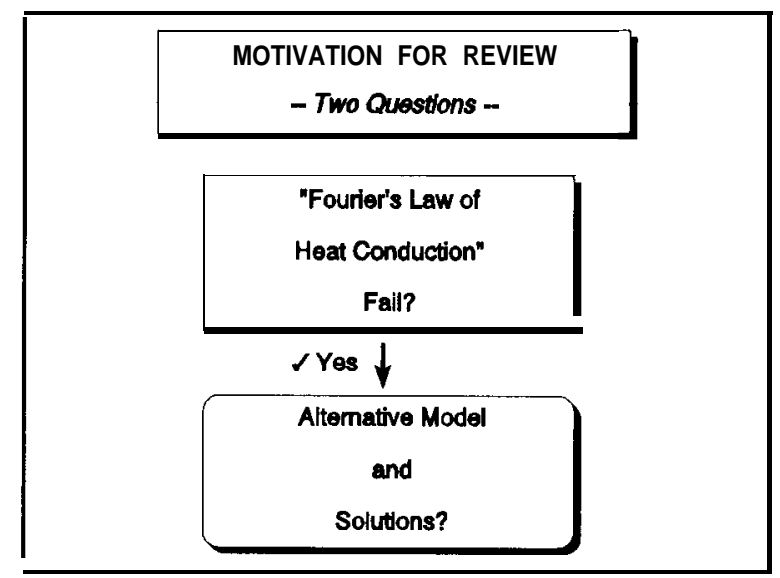

Fig. 3. Focal Point slide for conference paper

I judged the first question in the flowchart would get attention from the audience, since the failure of Fourier's Law generates the need to learn about alternative models. Then, by stating: "By the end of this talk I'll show that we have alternative models, "I judged the audience would be motivated to listen further.

\section{Conclusion}

In conclusion, properly selecting a title and focal point helps create initial interest in a presentation. The selection effort is worthwhile, since this interest is often difficult to capture. However, this interest is only one element of a successful presentation. Other elements include an interesting and persuasive story of the technical work described, designing the presentation to achieve the speaker's goals, slides (visual aids) the audience can easily understand, and a delivery that reinforces and gives life to the slides.

\section{References}

1. Antaki P. J., "The Benefits of Using Case Studies to Teach Technical Presentation Skills," Proceedings of the 1993 ASEE/IEEE Frontiers in Education Conference.

2. Antaki P. J., "Designing and Delivering Technical Presentations," Mechanical Engineering, pp 63-65, v114, n4, (1992).

\section{PAUL J. ANTAKI}

Paul is the principal engineer of Antaki \& Associates Inc., in Mercerville, NJ. The firm specializes in thermal analysis and design, and training for technical presentations. He earned his Ph.D. in mechanical and aerospace engineering from Princeton University, and M.E. and B.E. in mechanical engineering from Cooper Union. He is a licensed professional engineer in New Jersey. 